\title{
A Brief Analysis of Relations between Traditional Culture and Personal Cultivation from the Perspective of Intercultural Communication
}

\author{
Hengbo Yang \\ Qujing Normal University, QJU, Qujing, China
}

Keywords: Traditional culture; Personal cultivation; Personal development

\begin{abstract}
It is universally accepted that personal cultivation plays a crucial role in interpersonal relationship and social development. In the $21^{\text {st }}$ century, with the mixture of cultures, the essence of traditional culture should be valued highly. For the purpose of building a homonious, stable interpersonal relations and facilitating people's initiativeness in paticipating social activities, personal marality cultivation is an important issue that should be taken into consideration. In Chinese culture, a lot of outstanding cultural heritage can be learned to develop personal cultivation such as honour the rites, honour the honesty, honour the wisdom.
\end{abstract}

\section{Introduction}

With the development of sociey, there are diversified cultures coexisting with the mainstream culture. In China, thanks to its long history and civilization, the traditional culture as an impotant factor is always facilitating the develoment of society as well as the growth of each individual. In the 21 century, this cultural heritage still plays its important role in buiding personal relations with different societies. In a sense, mastery of the essebce of traditional culture has become a major ideology that impacts a nation's development. As scholars stated" What ethnic is what worldwide".

Man is the main factor of society. A person's morality is closely related to his role in the social activities. In other words, personal cultivation is very important to the development of interpersonal relations and the establishment of healthy, harmonious and stable society. Based on the traditional Chinese culture, there are outstanding cultural heritage can be found to influence the personal cultivation.

\section{The Data Collection through the Questionaire}

In order to have a good understanding of the relations between the traditional culture and personal cultivation, a questionaire has been designed among the people from different backgrounds. There are ten questions involving peoples' attitudes and cognitions based on their life and work. The following are the details of the questionaire.

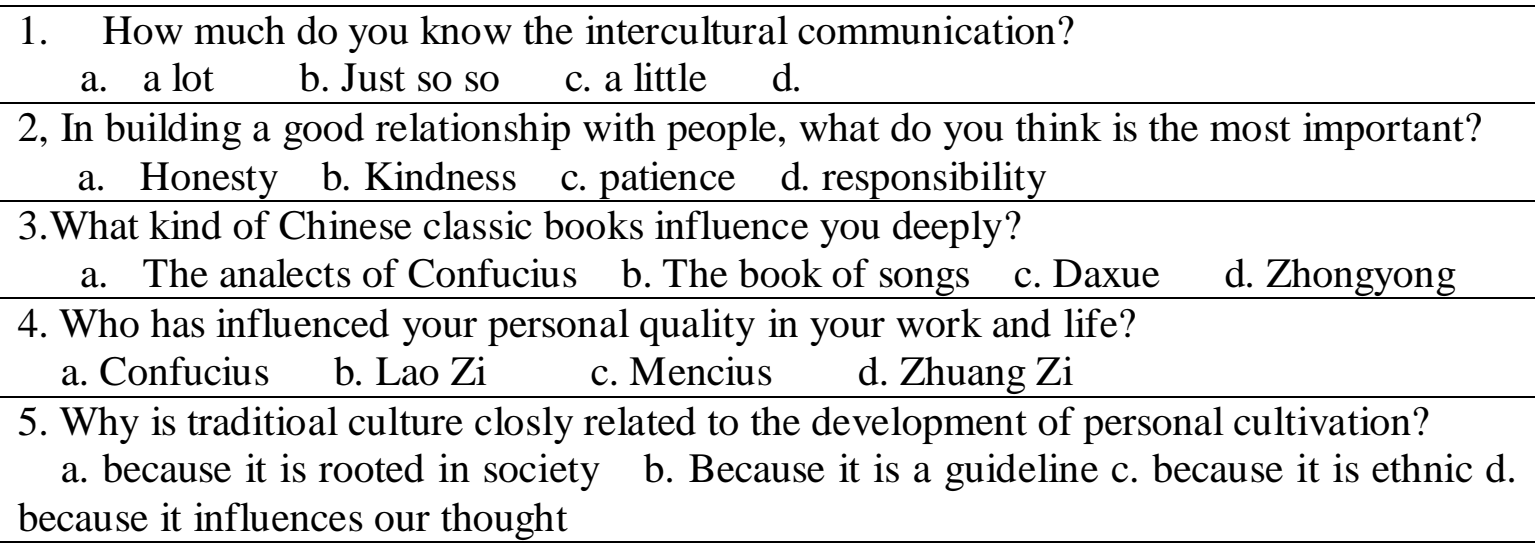




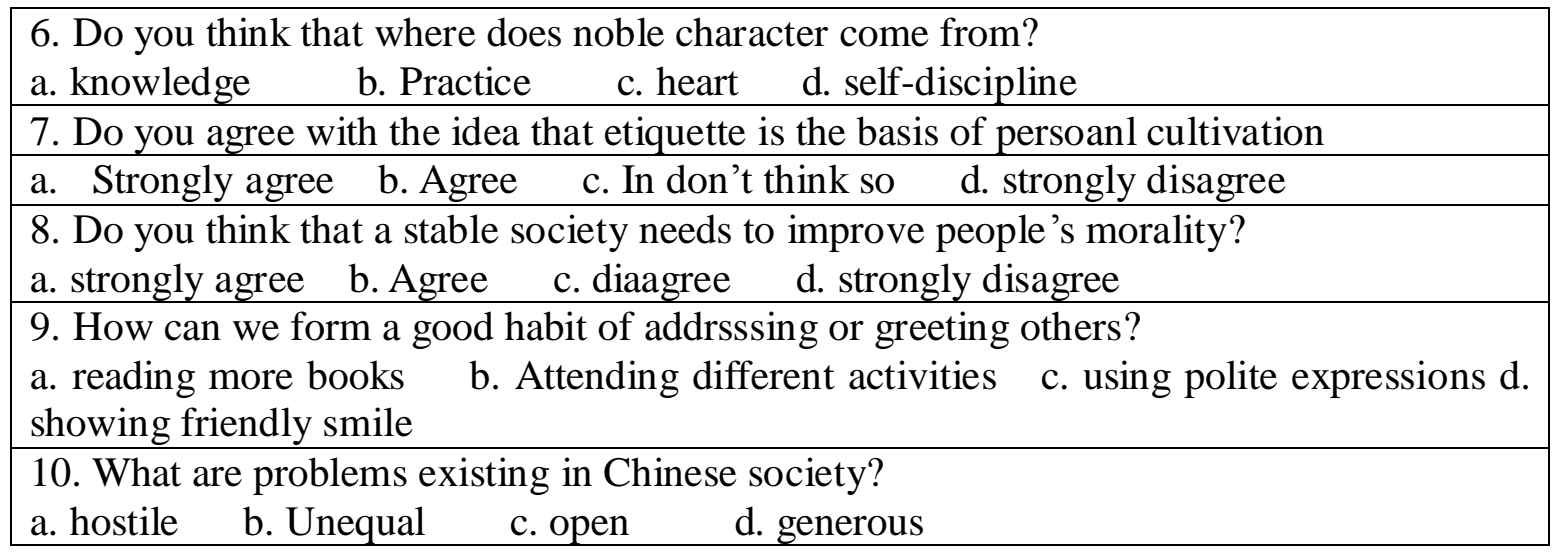

Based on the questions above, 157 paticipants were asked to choose the answer. The result reveals the diffference and similarities. For the first question, just $49 \%$ know about the intercultural communication; For questions from 2 to 5,89\% participants answered in the same way. For question 6, the answer is different. For question 7 and 8, participants have the same agreement. Questions 9 and 10 are different.

\section{The Analysis of the Data from Questionaire}

From the results of the questionaire, it is obvious that personal morality cultivation is mainly determined by differnet factors such as environment, knowledge, values, beliefs, etc. In the Chinese society, there is a positive setting where each individual seeks his life career differently. However, according to the data analysis, the traditional Chinese cultural values, together with social values, are motivating people to become useful and qualified citizens. There is no doubt that the essence of Chinese traditional culture is spreading in every corner of society, which has cultivated people's character in terms of ethic morality.

\section{Some Major Moral Qualities Influncing Personal Cultivation}

\section{Advocating Etequette Is the Basis of Personal Cultivation}

Etiquette is considered to be the basical moral rule in Chinese traditional culture in terms of interpersonal relationship. There are three points from the perspectives of ethics. First is that etiquette is the universal moral rule in society. The second is that Etiquette has its special conotation. The third is that etiquette means how to treat people and to deal with the things. In Chinese culture, Confucinism dominates every aspect of society. The major core of Confuciism advocates morality which includes maral character, justice and integraty. According to the Confucius, he poined out that the general can be replaced but a person's amition is not. Hec also proposed benevolence which is the impotant quality of how to deal with relations in regard to the parents, brothers and friends. Among the relations of individuals with family, individual with country, he strongly advocated the importance of the public awareness.

\section{Advocating of Honesty is Another Basic Quality in Building Well-Off Society.}

In the eyes of Pre-Qin Confucinism, honesty is hghy perferrd. Mencius said" Honesty is the principle of the heaven and the fundamental of the man." Xunzi also stated that A good man is relying on his integraty instead of other things. Honesty expresses that one should be true to himself. In the Chinese traditional culture, it advocates the righteousness which indicates the spirit of personal 
morality cultivation. Xuncius proposed that a man of noble charater is expresed through his integraty which is learned from the daily practice. If so, a man of noble character is called selfishless and he always thinks of others.

\section{Advocating Self-Introspection and Tolerence}

According to the Chinese culture, the ultimate aim of morality is to reach the combination between heaven and earth. It stresses that as an individual living in society, he should be making progres and be tolerate in dealing with things and getting on well with each other.. Only in this way personal cultivativation will be done. In order to realize one's personal cultivation, he should abide by the rules and constantly change the bad behaviors to acquire the etiquette. Based on the Confucian teachings, one should emulate those better than himself and get rid of prejudice on those who are better or bad.

\section{Advocating an Attitude of Removing One's Worries and Controling One's Desires}

In the traditional Chinese culture, it advocated that a man is required to live in a moderate way both in life and work. Do not worry about what is going on around you. He should remove anxieties or worries by means of thinking moderately. Do not desire so much which will lead to a greed. In terms of materialism, try not to be voracius. Maintain a happy state of mind and life. Man is encouraged to pursue life value which is the high peak of personal cultivation.

\section{Advocating a Sipit of Striving to Become Stronger}

According to the Book of Changes, man should follow heaven to become stonger. Universe is vigorous. Man should be like universe to make himself struggle constantly. To have selfmotivation, selfesteem, inntiativeness is what a person should constantly do in his lifetime. Laos said that knowing others is called wise while knowing oneself is wiser; conquering others is powerful, while finding one's mistakes is more powerful.

\section{Advocating the Wisdom}

Wisdom is the basic morality in the traditional Chinese culture. In the eyes of Confucianism, wisdom means people should be clear of what is wrong and what is right. Wisdom warns people not to be confused and deceived. In dealing with situations, people should have prediction of what potential problems will arise. In other words, when conducting things, people are required to check erroneous idea at the outset. If everyone realizes this, he or she is called a wise man. Motse advocated in his works: "a wise man focuses on thinking instead of talking and doing more in stead of taking credits". Boasting and exaggerating is not preferrred. For it will cause a kind of inharmony.

\section{Advocating Self-Discipline and Social Committment}

In the Chinese culture, there is one statement that is a man of noble character always behaves himself based on self-discipline and social committment. This strongly expresses what a man should do in society. In social setting, a man as an indivdual is closely related to the social activities including participation, involvement, role play, etc. In order to reach a certain goal of achievement, man is required to possess self-disciline which is the basis of moral character. In social life, an individual involves himself by showing his philanthropism such as friendly communication with others, taking care of others, thinking of others and developing interpersonal relations with others. For achieving life value, an individual should make constant efforts to realize his aim, then his harvest in career can make himself enjoyable and successful. This harvest means that an individual 's growth is in relation to the 
development of society. That is to say, social committement reflects an individual's devotion or contribution.

\section{Advocating the Concept of Knowing Ones' Mistake and Correcting It.}

According to Laozi, he proposed that it was a wisdom to know other people's character, and it was wiser to know oneself. In our daily life, man always ignores his shortcoming and fails to identify his problems. This really does harm to a person's character cultivation. In society, being a wise man will bring much benefits to the environment.

\section{Summary}

Personal cultivation or personal morality is of importance to the development of society. In China, with the increasing growth of economy, people's morality or personal cultivation is being improved. However, a few of Chinese citizens behave in a rough way, which has damaged the image of China. So for protection of Chinese image on the world stage, it is our obligations to learn more good virtues from the traditional culture and to develop our personal morality.

\section{References}

[1] HU, Wenzhong and C.Grove. Encounting the Chinese: A guide for Americans. Yarmouth, Maine: Intercultural Press, Inc., 1991.

[2] Samovar, L.A, R.E. Porter. Intercultural Communication between Cultures Belmont: Wadsworth Publishing Company, 1999.

[3] Stern, H.H Fundamental Concepts of Language Teaching. Oxford: OUP, 1983.

[4] Ting-Toomey, S. Communicating Across Cultures. New York: The Guilford,1999 